\title{
The value of human connection in health care
}

\section{EDITORIAL}

\section{Moyez Jiwa}

The University of Notre Dame Australia, School of Medicine Sydney, Melbourne Clinical School, Werribee, VIC, Australia

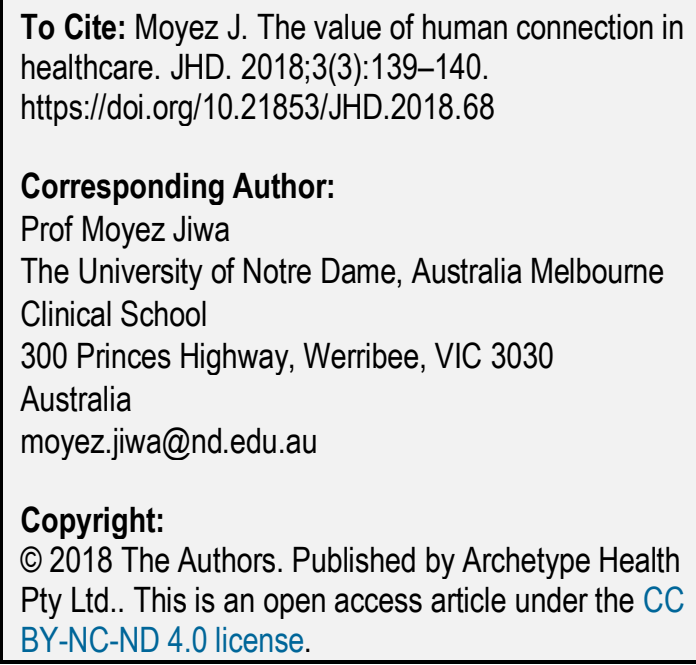

\section{Corresponding Author:}

Prof Moyez Jiwa

The University of Notre Dame, Australia Melbourne

Clinical School

300 Princes Highway, Werribee, VIC 3030

Australia

moyez.jiwa@nd.edu.au

\section{Copyright:}

(C) 2018 The Authors. Published by Archetype Health

Pty Ltd.. This is an open access article under the CC BY-NC-ND 4.0 license.

\section{SUMMARY}

The perfect healthcare policy, one which leads to the best possible outcomes in every case, remains elusive. Throwing money at health care has not led to better results. Most people will seek help with a medical problem for which there is no "cure". The best that can be offered is symptom management and waiting patiently for the body to heal itself. The quality of the interaction between doctor and patient is what has the greatest bearing on the outcome in an individual case. Forging the most effective connection with the patient involves simply asking more questions. Interrupting less. Remaining curious. Maintaining eye contact. Clarifying. Simplifying. Smiling Examining. Pausing. It's not sufficient, but it is necessary.

\section{Key Words}

Consultation; health care; policy; art; communication

\section{INTRODUCTION}

Inequity in healthcare outcomes is a major preoccupation for all concerned: voters, politicians, and bureaucrats. ${ }^{1}$ Some people who seek medical advice are being over-serviced. Others are dismissed even when they present with fulminant treatable pathology. Is it a question of introducing the "right" healthcare policy? Every incoming government will reform policy and its successor will reverse those policies in favour of another ideology. Therefore, given this never ending cycle of reform and the upward spiraling costs of health care, the successful search for the "right" policies remains elusive.

Nor could it simply be a case of spending the right amount per person. Spending on health care in the United States is far greater than what is invested in health care in a country like Australia and yet dollar for dollar Australia performs as well if not better on most healthcare outcomes. ${ }^{2}$ This fact suggests that outcomes won't simply improve with increased government spending.

If it isn't the cost of health care or the policies that dictate who is able to access health care and when, what could it be? There is no getting away from the detail of what happens when people need medical advice. For the patient it starts with recognising that there is a need to consult a doctor. At that point the outcomes are fluid. It is possible that the interaction with the health professional will either end with improvement, not to say recovery, or promote delay if not disaster.

The key point is that the interaction with the healthcare professional has an enormous bearing on the outcome. That interaction is not a simple commercial exchange where a person expresses a need, is offered a service or good, pays for it, and leaves satisfied. It's not like buying a book from Amazon. And yet it sometimes appears that health policies are fashioned as though health care were like buying a commodity. What drives reform is the idea that people simply need to access any practitioner who has tangible resources that will resolve problems efficiently, and the notion that resources can be doled out in measurable ways covered in a digestible sugar coating. As long as these two elements are present, we are led to believe good outcomes are certain. An entire industry benefits from and therefore promotes this delusion.

What might resolve a problem that a person presents to a healthcare practitioner is not necessarily a pill, potion, or procedure. In most cases there is no valid or reliable technical fix it. Most people will go to a doctor with problems for which there is no cure. Whether it is as life-limiting as dementia or as short lived as the common cold, doctors will 
rarely have a quick fix for any of their patients-syringing ear wax being a notable exception. There is no one-size-fits-all treatment for irritable bowel syndrome or eczema. The context in which people present with problems has an enormous bearing on the etiology. It matters what a person does for a living, it matters who is at home with them. It even matters what time of year it is and what the person eats, drinks, and does in their free time. It matters what the person believes is wrong with them, what the person thinks is required for treatment, and what they are dealing with at the same time as their tummy ache or itchy rash.

It seems bizarre that in 2018 in considering this issue experts might so readily be divorcing the person from their environment. The practitioner is now considered little more than a technician who can be financially incentivised. We have known for generations that the consultation, the meeting between doctor and patient is of enormous importance to the prognosis; ${ }^{3}$ that people are not rational in their decision-making; and that the principal of autonomy, the right to choose what we consider in our best interests, is the foundation of modern health care. That points to the one thing that we know makes a difference to the person in distress-human connection. It is an effective connection that helps people to see a "viral" upper respiratory infection for the self-limiting nuisance that it is, rather than the need for an antibiotic. It is that connection that allows the patient to glimpse behind their distress and see that working in that place or living with that person is causing that rash or those headaches.

Forging that connection requires practitioners to do relatively simple things. Introduce themselves. Shake the person's hand. Display the props that engender trust. ${ }^{4,5}$ Ask more questions. Interrupt less. Be curious. Maintain eye contact. Clarify. Simplify. Smile. Examine. Pause. These are not mere niceties. This isn't just being polite-although it is that, too. This is doing what the job requires. The world doesn't need to wait for a magic bullet. Everyday those who are involved in delivering health care learn something that adds to the ability to improve the prospects for recovery from illness.

\section{REFERENCES}

1. Friel S, Marmot MG. Action on the social determinants of health and health inequities goes global. Annu Rev Public Health. 2011;32(1):225-36. doi: 10.1146/annurev-publhealth-031210-101220

2. Anderson GF, Hussey PS, Frogner BK, et al. Health Spending In The United States And The Rest Of The Industrialized World. Health Affairs. 2005;24:4.903-14.

3. Stewart MA. Effective physician-patient communication and health outcomes: a review. CMAJ: Canadian Medical Association Journal. 1995;152(9):1423-33.

4. Jiwa M, Millett S, Meng X, et al. Impact of the Presence of Medical Equipment in Images on Viewers' Perceptions of the Trustworthiness of an Individual On-Screen. Journal of Medical Internet Research. 2012;14(4):e100. doi:10.2196/jmir.1986.

5. Jiwa M. Deploy tools that are essential to the office and alchemy of healing. The Journal of Health Design. 2016;1(3):6-8. doi:10.21853/JHD.2016.18

\section{ACKNOWLEDGEMENTS}

None

\section{PEER REVIEW}

Not commissioned. Externally peer reviewed.

\section{CONFLICTS OF INTEREST}

The authors declare that they have no competing interests.

\section{FUNDING}

None

\section{ETHICS COMMITTEE APPROVAL}

None 